\title{
Unusual presentation of multiple endocrine neoplasia type 1 in a young woman with a novel mutation of the MEN1 gene
}

Received: 8 March 2004/ Accepted: 20 April 2004/Published online: 16 June 2004

(C) The Japan Society of Human Genetics and Springer-Verlag 2004

\begin{abstract}
We report an unusual presentation of multiple endocrine neoplasia type 1 (MEN 1) in a young woman who was subsequently proven to have a novel mutation of the MEN1 gene. The young patient, aged 25 years, was investigated for abdominal discomfort and left upper abdominal pain. Her family history was unremarkable, except an unknown disorder of her father causing early death. Abdominal ultrasonography (USG) and computed tomography revealed a giant pancreatic tumor measuring $10 \mathrm{~cm}$ in diameter. The diagnosis of a clinically nonfunctioning pancreatic neuroendocrine tumor was established by clinical and other studies, including USG-guided aspiration biopsy and octreotide scintigraphy, and the patient underwent a distal pancreatectomy. Histology proved a well-differentiated multinodular neuroendocrine tumor of the pancreas. During surgery, a subcutaneous lipoma was also removed from the abdominal wall. Two years later, the patient developed primary hyperparathyroidism, and two enlarged parathyroid glands were surgically removed. Magnetic resonance imaging of the pituitary gland was normal. Screening for MEN1 gene mutation by temperature gradient gel electrophoresis revealed heterozygosities in exons 3,8 , and 9, while direct sequencing indicated a novel germline mutation (C354X) resulting in a stop codon in exon 8 and poly-
\end{abstract}

K. Balogh · A. Patócs $\cdot$ J. Majnik $\cdot$ K. Rácz $(\bowtie)$

Second Department of Medicine, Faculty of Medicine,

Semmelweis University, Szentkirályi str. 46,

1088 Budapest, Hungary

E-mail: racz@bel2.sote.hu

Tel.: + 36-1-2660816

L. Hunyady

Department of Physiology, Faculty of Medicine,

Semmelweis University, Budapest, Hungary

F. Varga

First Department of Medicine, Faculty of Medicine,

Semmelweis University, Budapest, Hungary

G. Illyés

Second Department of Pathology, Faculty of Medicine,

Semmelweis University, Budapest, Hungary morphisms in exon 3 (R171Q) and exon 9 (D418D and L432L). Genetic screening revealed no mutation in living family members. Our unusual case suggests that a multinodular pancreatic neuroendocrine tumor in a young patient may justify screening for MEN 1 syndrome, even in the absence of other endocrinopathy or family history.

Keywords Genetic screening - Germline mutation • Multiple endocrine neoplasia type $1 \cdot$ Neuroendocrine tumor · Polymorphism - Temporal temperature gradient gel electrophoresis

\section{Introduction}

Multiple endocrine neoplasia type 1 (MEN 1; OMIM 131100) is an autosomal dominantly inherited syndrome characterized by the combined occurrence of tumors of the parathyroid glands, endocrine pancreas, and anterior pituitary gland (Brandi et al. 2001). In addition to these major lesions, several others may also occur, although less frequently, in MEN 1 patients, e.g., adrenal cortical tumors, facial angiofibromas, lipomas, neuroendocrine tumors, thyroid neoplasms, pheochromocytomas, malignant melanomas, and testicular teratomas. The prevalence of MEN 1 syndrome is usually estimated as $1 / 30,000-1 / 50,000$, but it may be higher in some limited areas (Sakurai et al. 1998). The age of onset ranges from 6 to 81 years.

The MEN1 gene is a tumor suppressor gene, which is localized in chromosomal locus 11q13. Germline mutations of the MEN1 gene are associated with the MEN 1 syndrome. The gene consists of one untranslated exon and nine exons encoding the 610 amino acid protein, menin. Menin has no homology to any other known proteins (upon its interactions, it is considered to be involved in cell growth regulation, cell cycle, genome stability, and synapse plasticity). Previous studies have identified more than 400 germline and somatic muta- 
tions spreading across all the coding sequence (Pannett and Thakker 1999). Most of the mutations predict premature protein truncation. There is no mutational "hot spot," and clear genotype-phenotype correlation is also absent (Hoff et al. 2000; Kouvaraki et al. 2002).

The clinical symptoms of MEN 1 syndrome are mostly dependent on the involved glands and the presence of hormonal hypersecretion. The most common lesion is primary hyperparathyroidism, which often develops as the first manifestation of the MEN 1 syndrome, although as many as one third of gene carriers do not present with hyperparathyroidism as the first feature (Glascock and Carty 2002). The second most frequently expressed manifestation is neoplasia of the pancreatic islets, which includes gastrinoma, insulinoma, and, less frequently, other islet tumor types (Glascock and Carty 2002). In addition, pancreatic lesions with characteristic histological features of neuroendocrine tumors but without clinically relevant symptoms are also detected in MEN 1 patients. In most MEN 1 patients, these pancreatic endocrine and neuroendocrine tumors are diagnosed later in life (Baudin et al. 1999), usually many years after the diagnosis of primary hyperparathyroidism. In agreement with these observations, germline mutations of the MEN1 gene have rarely been detected in patients presenting with apparently sporadic neuroendocrine tumors (Baudin et al. 1999; Cupisti et al. 2000), except in those with gastrinomas or multiple isletcell tumors (Brandi et al. 2001).

We report here a young woman without family history of endocrinopathy who presented with a giant pancreatic neuroendocrine tumor as the first feature of MEN 1 syndrome. Furthermore, we also show in this patient a novel germline mutation $(\mathrm{C} 354 \mathrm{X})$ resulting in a stop codon in exon 8 of the $M E N 1$ gene.

\section{Subjects and methods}

\section{Subjects}

In 1998, a 25-year-old woman presented with abdominal discomfort and left upper abdominal pain. Her family history was unremarkable, except for an unknown disorder of her father causing an early death. The physical examination and routine laboratory tests were normal, including serum calcium and phosphorous levels. Abdominal ultrasonography (USG) and computed tomography discovered a giant pancreatic tumor measuring $10 \mathrm{~cm}$ in diameter (the stomach was dislocated by the tumor, but pathological lymph nodes were absent). USG-guided aspiration biopsy was performed, and evaluation of the specimen was indicative for a pancreatic neuroendocrine or carcinoid-type tumor. Somatostatin receptor scintigraphy (SRS) with indium-111 OctreoScan was also performed and showed intense isotope accumulation within the lesion. Based on these findings, the diagnosis of a clinically nonfunctioning pancreatic neuroendocrine tumor was established, and the patient underwent a distal pancreatectomy. The tumor was separated by enucleation from the pancreas head. During surgery, a subcutaneous lipoma measuring $3 \mathrm{~cm}$ in diameter was found and removed from the abdominal wall. Pathological examination of the surgically removed pancreatic specimen revealed a giant tumor of a nodular appearance with a maximum size of $11 \mathrm{~cm}$ accompanied by two smaller lesions within the tail of the pancreas (Fig. 1). Two years later, the patient developed primary hyperparathyroidism, as evidenced by raised serum calcium (3.1 mmol/l; normal range, $2.15-2.55 \mathrm{mmol} / \mathrm{l})$ and parathyroid hormone levels $(72 \mathrm{pg} / \mathrm{ml}$; normal range $10-65 \mathrm{pg} / \mathrm{ml})$. Preoperative parathyroid scintigraphy indicated a parathyroid adenoma on the lower pole of the left thyroid lobe. As the presence of MEN 1 syndrome was still unrecognized, the patient was considered as having sporadic parathyroid adenomas, and during exploration, the two enlarged parathyroid glands located at the lower poles of the right and left thyroid lobes were removed. During surgery, the upper right and left parathyroid glands were not explored. After parathyroid surgery, the serum calcium and parathyroid hormone levels decreased, but mild primary hyperparathyroidism persisted throughout the follow-up period lasting until presently.

The presence of persisting hyperparathyroidism after parathyroid surgery, together with the histological finding of nodular hyperplasia in the two removed parathyroid glands, and the history of a nonfunctioning multinodular pancreatic neuroendocrine tumor prompted us to consider the diagnosis of MEN 1 syndrome. The presence of pituitary tumor was excluded by magnetic resonance imaging and pituitary hormone measurements. During follow-up, the patient remained asymptomatic, and regular screening for pancreatic tumor recurrence or pituitary tumor development gave negative results.

To reveal the disease-causing mutation, genetic screening of the MEN1 gene with temporal temperature gradient gel electrophoresis (TTGE) and direct DNA sequencing was performed. Written informed consent

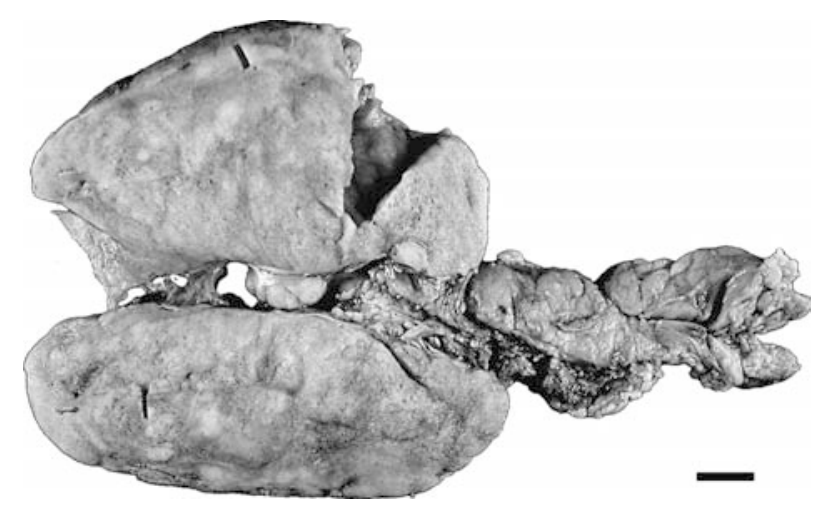

Fig. 1 Specimen of distal pancreatectomy shows a giant tumor, which was enucleated from the pancreatic head. $(\mathrm{Bar}=1 \mathrm{~cm})$ 
for genetic testing was obtained from the patient and the relatives. Genetic studies were performed in the patient and in her mother and brother, as the patient had no other living family members. Clinical studies in the mother and brother failed to show any signs of MEN 1 syndrome.

\section{Mutation analysis}

Genomic DNA was prepared from peripheral blood samples using a DNA isolation kit (Roche $\mathrm{GmbH}$ Mannheim, Germany) according to the manufacturer's instructions. For each PCR reaction, 200-400 ng DNA was used as a PCR template in $50 \mu \mathrm{l}$ final volume for the amplification of the screened exon. PCR reactions were performed with the following primers: exons 5 and 6, amplified in one DNA fragment: F, 5'-GGCTCATAACTCTCTCCTTC-3'; R, 5'-CACTGTTAGGGTCTCCCTTC-3'; exon 8: F, 5'-CAGACCCTACAGAGACCCCAC-3'; R, 5'-CCATCCCTAATCCCGTAC-3'; primers for all other exons were designed upon the study of Morelli et al. (2000).

\section{TTGE}

One primer from each pair contained a 40-base GC-rich sequence (GC clamp) to prevent complete denaturation of the PCR product during the electrophoresis. The reaction mixture contained 15 and $35 \mathrm{pmol}$ of the GCclamped and regular primer, respectively, $0.2 \mathrm{mmol} / 1$ of each deoxynucleotide, and $2 \mathrm{U}$ of Sigma Taq DNA polymerase (Sigma-Aldrich Corp., Saint Louis, MO, USA). An initial $95^{\circ} \mathrm{C}$ denaturation step for 5 min was followed by 35 cycles of denaturation at $95^{\circ} \mathrm{C}(1 \mathrm{~min})$, annealing step at specified temperature (1 $\min 30 \mathrm{~s})$, and extension step at $72^{\circ} \mathrm{C}(1 \mathrm{~min} 30 \mathrm{~s})$. The final extension step was performed for $5 \mathrm{~min}$ at $72^{\circ} \mathrm{C}$. The amplicons were allowed to form heteroduplexes at room temperature for $1 \mathrm{~h}$ after denaturation at $95^{\circ} \mathrm{C}$ for $5 \mathrm{~min}$. For all exons of the MENl gene, PCR products were screened using TTGE, which involved electrophoresis of doublestranded DNA fragments through a polyacrylamide gel containing a constant concentration of denaturant (urea). During electrophoresis, the temperature of the buffer increased gradually, providing a linear temperature gradient. TTGE analysis was performed using DCode universal mutation detection system (Bio-Rad, Munich, Germany). Theoretical melting profiles of the amplified fragments were calculated and graphed by WinMelt software (Bio-Rad). Adding urea to the gel can decrease the theoretical melting temperatures (each mole per liter urea decreases the melting temperature by $2^{\circ} \mathrm{C}$ ). Electrophoresis was achieved for $5 \mathrm{~h}$ at $140 \mathrm{~V}$ on $8 \%$ acrylamide/bis-acrylamide (37.5:1) gel containing $8 \mathrm{M}$ urea with 1.5× TAE buffer. Gels were stained with ethidium bromide and visualized by a Fluor-S MultiImager (Bio-Rad).

\section{DNA sequencing}

To identify the genetic alterations revealed by TTGE, PCR-amplified exons were sequenced by ABI PRISM BigDye Terminator Cycle Sequencing kit (Perkin-Elmer, Foster City, CA, USA). Automated DNA sequencing was performed using the same primers without adding the GC clamp. Family screening was also performed by DNA sequencing.

\section{Results}

\section{Histology}

Histological evaluation showed that the pancreatic tumor consisted of cells with endocrine characters, which were arranged in a trabecular or a solid structure (Fig. 2a and b). There were no mitoses or signs of invasion. The tumor cells were positive for cytokeratin, S100 antigen, synaptophysin (Fig. 2c) (mouse anti-human monoclonal antibody; DAKO Corp., Carpinteria, CA, USA, Code No. M0776), chromogranin A (Fig. 2d) (mouse anti-human monoclonal antibody; DAKO Code No. M0869) and neuron specific enolase (Fig. 2e) (Mouse anti-human monoclonal antibody, DAKO Code No. N1557) by immunohistochemistry. Glucagon, serotonin, gastrin, somatostatin, and estrogen receptor were absent. In one small nodule of the tumor, insulin immunoreactivity was detected (Fig. 2f) (Guinea pig polyclonal anti-insulin, DAKO Code No. 1542). Histology of the subcutaneous lipoma was classical. Histological examination of the parathyroid glands revealed nodular hyperplasias.

\section{TTGE}

Using TTGE, multiple electrophoretic bands suggesting heterozygous genetic alterations were found in exon 8 (Fig. 3a) as well as in exons 3 and 9 of the patient. All other exons of the patient showed single electrophoretic bands similar to those detected in control subjects.

\section{Direct sequencing}

Sequencing of exon 8 in both directions on a new PCR product revealed the presence of a heterozygous nonsense mutation (C354X) (Fig. 3b). To our knowledge, this mutation has not been previously described in patients with MEN 1 syndrome. Since this mutation predicts a large truncation of menin, and large truncations reportedly interfere with the function of protein (Pannett and Thakker 1999), we assume that the presence of this novel mutation was responsible for the development of MEN1 in our patient. Genetic screening showed the absence of this novel mutation in the mother and brother of the patient. 

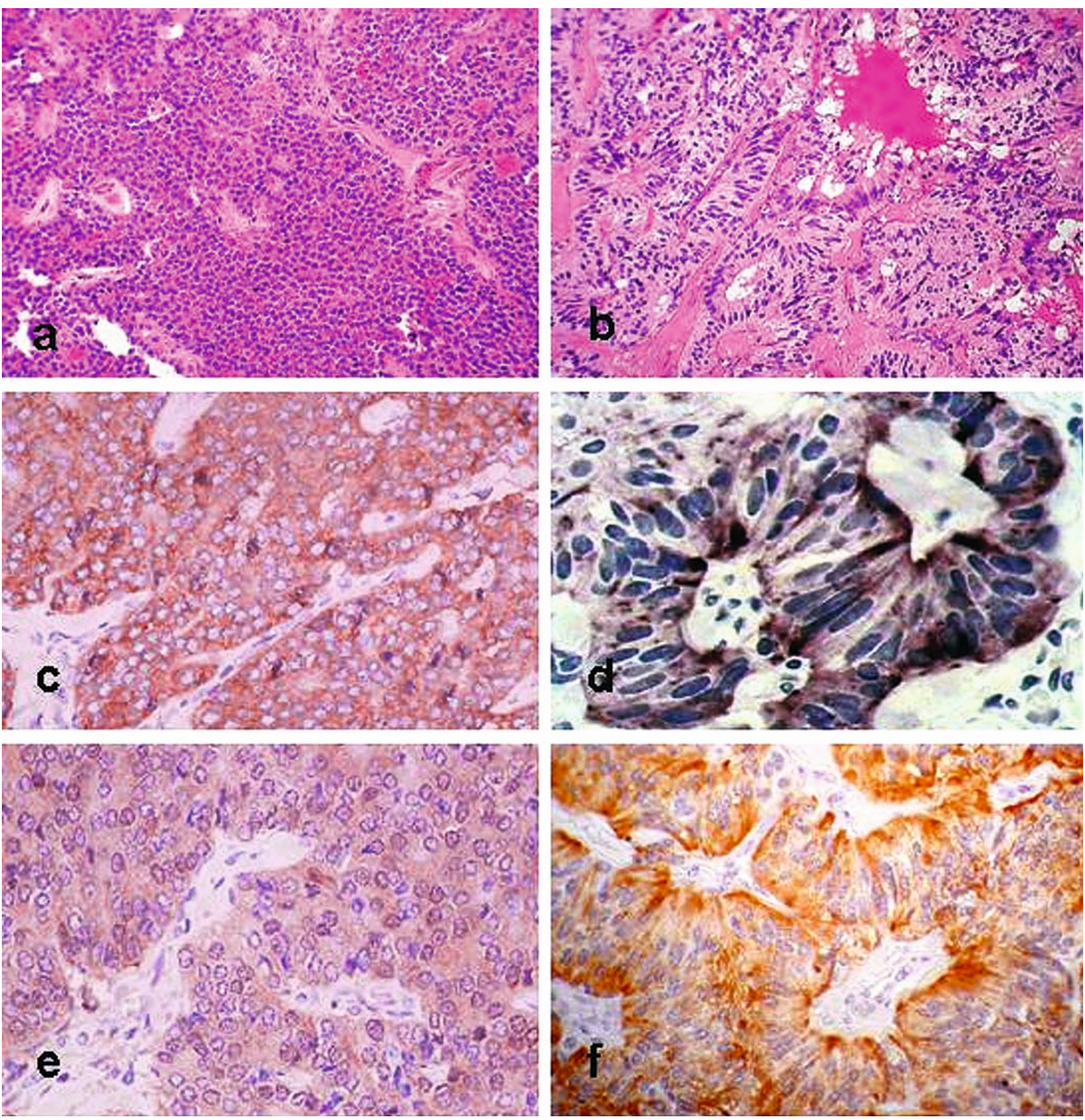

Fig. 2a-f Hematoxylin-eosin staining of the pancreatic tumor with nodules consisting of cells with endocrine characters; the structure is both a trabecular $(100 \times)$ and b solid $(200 \times)$. Brownish staining shows c synaptophysin $(400 \times)$, d chromogranin (600×), and e neuron specific enolase $(400 \times)$ reactivities in tumor cells and f insulin reactivity in a small tumoral nodule $(400 \times)$

Sequencing of exon 3 of the patient indicated that the abnormal electrophoretic bands detected by TTGE were due to a known polymorphism, which was present in a heterozygous form. This polymorphism that changes the amino acid arginine to glutamine at position 171 (R171Q) has been detected in $1.4 \%$ of the normal

population (Chandrasekharappa et al. 1997). Family screening indicated that mother and brother of the patient did not carry this polymorphism.

In agreement with findings obtained from TTGE analysis, sequencing of exon 9 of the patient showed two heterozygosities, which corresponded to a GA $C \rightarrow$ GA $T$ change at codon 418 and a CTG $\rightarrow$ CTA change at codon 432 . Both of these changes are known polymorphisms, which do not alter the amino acid sequence of menin (D418D and L432L, respectively). Family screening indicated that the mother was heterozygous for D418D but L432L was absent. These 


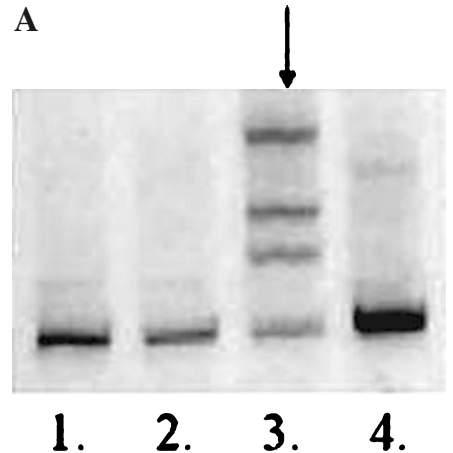

B

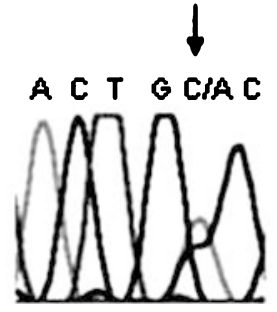

Fig. 3 a Analysis of exon 8 of the MEN1 gene by temporal temperature gradient gel electrophoresis (TTGE). The single electrophoretic bands in lanes 1, 2, and 4 correspond to PCR fragments from healthy individuals used as controls; in lane 3, the presence of four bands indicates heterozygosity of the patient. b Detection of a novel germline mutation in exon 8 of the MEN1 gene by direct sequencing. A heterozygous TGC $\rightarrow$ TGA change at amino acid position 354 results in a stop codon (C354X)

polymorphisms were not detected in the brother of the patient.

\section{Discussion}

Our patient, who was initially considered as having a sporadic pancreatic neuroendocrine tumor, later was found to show unusual features of MEN 1 syndrome based on clinical findings, and a novel germline mutation of the MENI gene was detected. As the major unusual manifestation of the MEN 1 syndrome, the patient developed a giant pancreatic neuroendocrine tumor, which presented with abdominal symptoms presumably related to a mass effect of the tumor. This presentation of MEN 1 syndrome was a rather uncommon finding, since giant pancreatic endocrine or neuroendocrine tumors have rarely been reported in MEN 1 patients (Kataoka et al. 1999; Lairmore et al. 2000). In addition, pancreatic endocrine and neuroendocrine tumors are usually slowly growing neoplasms, and in most MEN 1 patients, they are diagnosed after the age of 40 years (Brandi et al. 2001). Thus, the young age of our patient was also unusual for the development of a MEN 1-related pancreatic neuroendocrine tumor. Finally, the very large size of the tumor in our patient might be predictive of a malignant development (Lairmore et al. 2000; Sato et al. 2000), but no lymph node or distant metastases were present, and regular clinical evaluation failed to show a tumor recurrence during follow-up.
These observations suggest that a nonfunctioning pancreatic neuroendocrine tumor associated with MEN 1 syndrome may be indolent, independent of its size, as already proposed (Sato et al. 2000).

In our patient, the pancreatic neuroendocrine tumor, which was successfully removed by distal pancreatectomy, proved to be a multinodular neoplasm with a giant tumor surrounded by two smaller lesions within the tail of the pancreas. This finding supports recent proposals that multiple pancreatic endocrine tumors may be suspicious for MEN 1 syndrome and that in this clinical setting mutation screening should be indicated even in the absence of other criteria of MEN 1 syndrome (Brandi et al. 2001). Interestingly, the multinodular giant neuroendocrine tumor was negative for glucagon, serotonin, gastrin, somatostatin, and estrogen receptor by immunohistochemistry, but in a small nodule of the tumor, insulin immunoreactivity was detected. However, clinical and biochemical symptoms of hyperinsulinism were absent, suggesting that insulin production within this small nodule was not high enough to produce increased plasma insulin level. It is also interesting that in our patient, a subcutaneous lipoma within the abdominal wall was detected and removed during surgery, because cutaneous and visceral lipomas are reportedly present in up to one third of patients with MEN 1 syndrome (Trump et al. 1996). Also, cutaneous tumors have been suggested as possibly helpful indicators for presymptomatic screening of MEN 1 carriers (Darling et al. 1997). Thus, all these findings in our patient might have met the current proposal for mutation screening even before the development of primary hyperparathyroidism, which was diagnosed 2 years after surgical removal of the pancreatic neuroendocrine tumor.

Our study confirms that TTGE offers an efficient tool for the detection of heterozygosity in exons of the MEN1 gene. This method revealed heterozygosities in exons 3,8 , and 9 of the patient, while direct sequencing of the same exons indicated a heterozygous mutation in exon $8(\mathrm{C} 354 \mathrm{X})$ as well as heterozygous polymorphisms in exon 3 (R171Q) and exon 9 (D418D and L432L). To our knowledge, the C354X represents a novel germline mutation, which has not been previously detected in patients with MEN 1 syndrome.

The MEN1 gene encodes the 610 amino acid protein, menin (The European Consortium on MEN1 1997), which shows no significant homology with any other known proteins (Guru et al. 1998). In the structure of menin leucine zippers and nuclear localization sequences have been recognized. The first protein partners of menin are transcription regulators (menin represses transcriptional activation mediated by $\mathrm{JunD}$, and it interacts directly with three members of the nuclear factor family NF-KappaB) (Poisson et al. 2003). In addition, menin is necessary for the TGF $\beta$ signaling pathway at the level of Smad3 (Kaji et al. 2001). In the latter pathway, the GTPase activity of menin might play an important role (Yaguchi et al. 2002). Via these interactions, menin plays a role in cell-growth regulation, cell-cycle control, 
genome stability, and synapse plasticity (Guo and Sawicki 2001). It seems particularly important that the majority of the known mutations of the MEN1 gene produce a premature truncation of menin (Pannett and Thakker 1999; Park et al. 2003). Since the novel germline mutation in exon 8 of the MEN1 gene (C354X) detected in our patient also created a large truncation of menin, we propose that the presence of this novel mutation interferes with the function of menin and should, therefore, be responsible for the development of the MEN 1 syndrome. It appears that truncation of menin at amino acid position 354 results in a protein in which both leucine zippers and the GTPase consensus sequence are intact, but the two nuclear localization sequences of menin as well as those necessary for binding of interacting proteins are partially lost. With such a structure, it can be predicted that menin is incapable of entering the nucleus and that its binding to most interacting proteins is also impaired.

As genetic screening could not be performed in the father of the patient, it is difficult to propose whether the novel C354X mutation detected in our patient was a de novo germline mutation or inherited from her father. It cannot be ruled out that the unknown disorder which caused an early death of her father was associated with an unrecognized MEN 1 syndrome, but this possibility was not confirmed by clinical or genetic studies.

In addition to the novel C354X mutation, three previously described polymorphisms (L432L, D418D, and R171Q) were also detected in our patient (Cebrián et al. 2002; Chandrasekharappa et al. 1997). In a study by Chandrasekharappa et al. (1997), these polymorphisms were found in $0.7,42$ and $1.4 \%$ of normal chromosomes, respectively. Interestingly, one study indicated that the D418D polymorphism might be overrepresented in patients with sporadic primary hyperparathyroidism (Correa et al. 2002). R171Q and L432L polymorphisms were also detected in tissues from sporadic adrenal tumors (Görtz et al. 1999), phaeochromocytomas, and paragangliomas (Edström et al. 2000).

In conclusion, our young patient was initially considered as having a sporadic pancreatic neuroendocrine tumor, but she later was found to show unusual features of MEN 1 syndrome based on clinical findings and the detected germline mutation of the MEN1 gene. The germline mutation in exon 8 of the MEN1 gene (C354X) found in our patient represents a novel mutation, and it predicts a large truncation of menin similar to those reported in the majority of known mutations associated with MEN 1 syndrome.

\section{References}

Baudin E, Bidart J-M, Rougier P, Lazar V, Ruffié P, Ropers J, Ducreux M, Troalen F, Sabourin J-C, Comoy E, Lasser P, DeBaere T, Schlumberger M (1999) Screening for multiple endocrine neoplasia type 1 and hormonal production in apparently sporadic neuroendocrine tumors. J Clin Endocrinol Metab 84:69-75
Brandi ML, Gagel RF, Angeli A, Bilezikian JP, Beck-Peccoz P, Bordi C, Conte-Devolx B, Falchetti A, Gheri RG, Libroia A, Lips CJM, Lombardi G, Mannelli M, Pacini F, Ponder BAJ, Raue F, Skogseid B, Tamburrano G, Thakker RV, Thompson NW, Tomasetti P, Tonelli F, Wells SA, Marx SJ (2001) Guidelines for diagnosis and therapy of MEN type 1 and type 2. J Clin Endocrinol Metab 86:5658-5671

Cebrián A, Ruíz-Llorente S, Cascón A, Osorio A, Martínez-Delgado B, Benítez J, Robledo M (2002) A rapid and easy method for multiple endocrine neoplasia type 1 mutation detection using conformational-sensitive gel electrophoresis. J Hum Genet 47:190-195

Chandrasekharappa SC, Guru SC, Manickham P, Olufemi S-E, Collins FS, Emmert-Buck MR, Debelenko LV, Zhuang Z, Lubensky IA, Liotta LA, Crabtree JS, Wang Y, Roe BA, Weisemann J, Boguski MS, Agarwal SK, Kester MB, Kim YS, Heppner C, Dong Q, Spiegel AM, Burns AL, Marx SJ (1997) Positional cloning of the gene for multiple endocrine neoplasiatype 1 . Science 276:404-407

Correa P, Lundgren E, Rastad J, Akerström G, Westin G, Carling T (2002) Multiple endocrine neoplasia type 1 polymorphism D418D is associated with sporadic primary hyperparathyroidism. Surgery 132:450-455

Cupisti K, Höppner W, Dotzenrath C, Simon D, Berndt I, Röher HD, Goretzki PE (2000) Lack of MEN1 gene mutations in 27 sporadic insulinomas. Eur J Clin Invest 30:325-329

Darling TN, Skarulis MC, Steinberg SM, Marx SJ, Spiegel AM, Turner M (1997) Multiple facial angiofibromas and collagenomas in patients with multiple endocrine neoplasia type 1 . Arch Dermatol 133:853-857

Edström E, Mahlamaki E, Nord B, Kjellman M, Karhu R, Höög A, Goncharov N, Teh BT, Backdahl M, Larsson C (2000) Comparative genomic hybridization reveals frequent losses of chromosomes $1 \mathrm{p}$ and $3 \mathrm{p}$ in phaeochromocytomas and abdominal paragangliomas, suggesting a common genetic etiology. Am J Path 156:651-659

European Consortium on MEN1 (1997) Identification of the multiple endocrine neoplasia type 1 (MEN1) gene. Hum Mol Gen 6:1177-1183

Glascock M, Carty SE (2002) Multiple endocrine neoplasia type 1: fresh perspective on clinical features and penetrance. Surg Oncol 11:143-150

Görtz B, Roth J, Speel EJM, Krahenmann A, De Krijger RR, Matias-Guiu X, Muletta-Feurer S, Rütmann K, Saremaslani P, Heitz PU, Komminoth P (1999) MEN1 gene mutation analysis of sporadic adrenocortical lesions. Int J Cancer 80:373-379

Guo SS, Sawicki MP (2001) Molecular and genetic mechanisms of tumorigenesis in multiple endocrine neoplasia type-1. Mol Endocrinol 15:1653-1664

Guru SC, Manickam P, Crabtree JS, Olufemi S-E, Agarwal SK, Debelenko LV (1998) Identification and characterization of the multiple endocrine neoplasia type 1 (MEN1) gene. J Int Med 243:433-439

Hoff AO, Cote GJ, Gagel RF (2000) Multiple endocrine neoplasias. Annu Rev Physiol 62:377-411

Kaji H, Canaff L, Lebrun J-J, Goltzman D, Hendy GN (2001) Inactivation of menin, a Smad3-interacting protein, blocks transforming growth factor type beta signalling. PNAS 98:3837-3842

Kataoka H, Otsuka F, Yamauchi T, Kishida M, Takahashi M, Tamiya T, Mimura Y, Ogura T, Makino H (1999) Giant insulinoma in a patient with multiple endocrine neoplasia type I: a case report. Endocr J 46:429-435

Kouvaraki MA, Lee JE, Saphiro SE, Gagel RF, Sherman SI, Sellin RV, Cote GJ, Evans DB (2002) Genotype-phenotype analysis in multiple endocrine neoplasia type 1. Arch Surg 137:641-647

Lairmore TC, Chen VY, DeBenedetti MK, Gillanders WE, Norton JA, Doherty GM (2000) Duodenopancreatic resections in patients with multiple endocrine neoplasia type 1. Ann Surg 231:909-918

Morelli A, Falchetti A, Martineti V Becherini L, Mark M, Friedman E, Brandi ML (2000) MEN1 gene mutation analysis in 
Italian patients with multiple endocrine neoplasia type 1. Eur J Endocrinol 142:131-137

Pannett AAJ, Thakker RV (1999) Multiple endocrine neoplasia type 1. Endocr Relat Cancer 6:449-473

Park J-H, Kim I-J, Kang HC, Lee S-H, Shin Y, Kim K-H, Lim SB, Kang S-B, Lee KU, Kim SY, Lee M-S, Lee M-K, Park J-H, Moon S-D, Park J-G (2003) Germline mutations of the MEN1 gene in Korean families with multiple endocrine neoplasia type 1 (MEN1) or MEN1 related disorders. Clin Genet 64:4853

Poisson A, Zablewska B, Gaudray P (2003) Menin interacting proteins as clues toward the understanding of multiple endocrine neoplasia type 1. Cancer Lett 189:1-10

Sakurai A, Shirahama S, Fujimori M, Katai M, Itakura Y, Kobyashi S, Amano J, Fukushima Y, Hashizume K (1998)
Novel MEN1 gene mutations in familial multiple endocrine neoplasia type 1. J Hum Genet 43:199-201

Sato M, Kihara M, Nishitani A, Murao K, Kobayashi S, Miyauchi A, Takahara J (2000) Large and asymptomatic pancreatic islet cell tumor in a patient with multiple endocrine neoplasia type 1 . Endocr J 13:263-266

Trump D, Farren B, Wooding C, Pang JT, Besser GM, Buchanan KD, Edwards CR, Heath DA, Jackson CE, Jansen S, Lips K, Monson JP, O'Halloran D, Sampson J, Shalet SM, Wheeler MH, Zink A, Thakker RV (1996) Clinical studies of multiple endocrine neoplasia type 1 (MEN 1) QJM 89:653-669

Yaguchi H, Ohkuras N, Tsukada T, Yamaguchi K (2002) Menin, the multiple endocrine neoplasia type 1 gene product, exhibits GTP-hydrolizing activity in the presence of the tumor metastasis suppressor nm23. J Biol Chem 277:38197-38204 